\title{
Genetic Diversity of Moroccan Orobanche crenata Populations Revealed by Sequence-Related Amplified Polymorphism Markers
}

\author{
Mounia Ennami ${ }^{1,2}$, Fatima Zahra Briache ${ }^{1}$, Joseph Mbasani Mansi ${ }^{1}$, Fatima Gaboun ${ }^{1}$, Lamiae Ghaouti ${ }^{2}$, \\ Loubna Belqadi ${ }^{2} \&$ Rachid Mentag ${ }^{1}$ \\ ${ }^{1}$ National Institute of Agricultural Research (INRA), CRRA, Biotechnology Unit, Rabat, Morocco \\ ${ }^{2}$ Agronomic and Veterinary Institute Hassan II (IAV), Production, Protection and Plant Biotechnology \\ Department, Rabat, Morocco \\ Correspondence: Rachid Mentag, National Institute of Agricultural Research (INRA), CRRA, Biotechnology \\ Unit-Rabat, Morocco. Tel: 212-661-558-622. E-mail: rachidmentag@yahoo.ca
}

Received: January 10, 2017

Accepted: February 24, 2017

Online Published: March 15, 2017

doi:10.5539/jas.v9n4p164

URL: https://doi.org/10.5539/jas.v9n4p164

The research is financed by INRA-Morocco, MAPM; MESRSFC; and ARIMNet "Medileg Project".

\begin{abstract}
Orobanche crenata Forsk. is a root holoparasitic plant that affects legume species in Mediterranean basin especially in Northern Africa. This parasitic weed is particularly problematic in faba bean (Vicia faba L.) and lentil (Lens culinaris Medik.) fields. In Morocco, development of legume resistant/tolerant genotypes is considered the most economical and ecological control strategy against $O$. crenata. Efficient selection of resistant/tolerant cultivars requires prerequisite knowledge of the genetic diversity of the parasite. Thus, the present study focused on the assessment of the genetic diversity among and within Moroccan $O$. crenata populations, growing in faba bean fields, using Sequence-Related Amplified Polymorphism markers (SRAP). This marker system proved to be a powerful and an efficient tool for the evaluation of the genetic diversity among $O$. crenata populations. In fact, a total of 101 markers were identified and used for the Analysis of Molecular Variance (AMOVA), among which 98 bands were polymorphic (97.02\%), indicating considerable genetic variation of these $O$. crenata populations. However, at population level, low level of polymorphic loci was observed with a percentage ranging between $41.58 \%$ and $67.33 \%$. The Jaccard's similarity coefficient and Principal Coordinate Analysis ( $\mathrm{PCoA}$ ) showed a clear differentiation among $O$. crenata samples according to the geographical origin of each population. AMOVA analysis revealed also a large extent of variation among $O$. crenata populations $(60 \% ; p<0.010)$. Our outputs on molecular genetics of $O$. crenata combined with future epidemiological studies of these populations should clarify occurrence of $O$. crenata pathotypes and thereby validate the relevance of using multisite screening trials during breeding programs.
\end{abstract}

Keywords: Orobanche crenata, genetic diversity, SRAP markers, AMOVA, geographic origin, population structure

\section{Introduction}

Faba bean (Vicia faba L.) is one of the most important legumes worldwide. According to Food and Agriculture Organization (2015), it is grown in 58 countries, from temperate, tropical to hot and arid conditions. Faba bean is used as a source of protein and minerals in human diet and as a feed crop for animals (Crépon et al., 2010). Furthermore, it provides an important added value on agriculture, improving fertility and soil structure for sustainable yield crop (Herridge, Peoples, \& Boddey, 2008).

In 2014, the world production of dry seeds reached 4.3 Million tons (Mt) from a total cultivated area of 2.3 Million hectares (Mha) (Food and Agriculture Organization Statistical [FAOSTAT], 2015). Mainland China, is the leading country with a production of $1.595 \mathrm{Mt}$, followed by Ethiopia $(0.838 \mathrm{Mt})$, Australia $(0.308 \mathrm{Mt})$, France $(0.278 \mathrm{Mt})$, and Morocco (0.166 Mt) (FAOSTAT, 2015). Despite its importance, the area allocated to this legume species has been reduced in many countries (FAOSTAT, 2015). In Morocco, the cultivated area of faba bean has been reduced from a total of 5.70 Mha between 1980-1990 to 2.32 Mha between 2004-2014 (FAOSTAT, 2015). This yield instability was due mainly to biotic and abiotic constraints (Miguel, Nicolas, Elena, Rubiales, 
\& Karam, 2006; Rubiales et al., 2005). The most damaging of these stresses is Orobanche crenata Forsk. (Westwood, Yoder, Timko, \& dePamphilis, 2010), this parasitic weed can cause losses in may reach $90 \%$ of Morocco's crop production (Torres et al., 2006; Ennami et al., 2017). It connects to the host's root system from which it extracts micronutrients needs (Joel et al., 2007). O. crenata was considered among the seven noxious pests of economically important crops in the world (Parker, 2009). A number of strategies of root parasitic weed control have been developed and employed. Unfortunately, most of them have been unfeasible, uneconomical, hard to achieve, or have resulted in incomplete protection (Rubiales et al., 2009). The most feasible approach for controlling damage caused by these parasitic weed is the development of resistant genotypes (Ter Borg et al., 1994). However, the emergence of new Orobanche crenata populations could overcome host resistance (Verkleij \& Pieterse, 1991), which is an ongoing challenge for breeding (Rubiales et al., 2009). Thus, the genetic variability of parasites should be considered. Some authors (Dybdahl \& Lively, 1996; Thompson, 1994) have suggested that knowledge of the population structure of both the parasite and its host is necessary to fully understand the evolution of these pathosystems. Over the years, the study tools of genetic variation among Orobanche have progressed gradually from morphological and agronomic traits to molecular analysis (Román, Rubiales, Torres, Cubero, \& Satovic, 2001). Thus, several techniques based on DNA analysis were used, such as random amplified polymorphic DNA (RAPD) (Román, Rubiales, Torres, Cubero, \& Satovic, 2001), inter simple sequence repeat (ISSR) (Román et al., 2002; Westwood \& Fagg, 2004), amplified fragment length polymorphism (AFLP) (Gagne et al., 2000), and simple sequence repeat (SSR) markers (Pineda-Martos et al., 2014). Moreover, Sequence-Related Amplified Polymorphism (SRAP markers) is a simple and efficient molecular marker system, more reproducible than RAPDs ISSR, and SSR markers (Budak et al., 2004; Liu et al., 2008; Liu et al., 2006) and easier to assay than AFLPs (Ferriol et al., 2003). This technique is based on open reading frames (ORFs) using two primers (forward and reverse) for amplification. It was developed and demonstrated by (Li \& Quiros, 2001) in Brassica oleracea. The SRAP technique was very useful for the assessment of genetic diversity because it presents many merits over the other marker systems (Aneja, Yadav, Chawla, \& Yadav, 2012). It was used in assessing genetic diversity in many species, including lentil (Rana, Singh, \& Bhat, 2009), pea (Esposito, Martin, Cravero, \& Cointry, 2007), Alfalfa (Al-Faifi et al., 2013; Castonguay, Cloutier, Bertrand, Michaud, \& Laberge, 2010), mungbean (Aneja, 2010), quigke (Yang, Liu, Yang, \& Feng, 2015), broccoli (Yu, Zhao, Sheng, Wang, \& Gu, 2013), etc.

In Morocco, no information is available on the genetic structure of Moroccan O. crenata populations. Also, as no attempts using SRAP targeting ORFs as function regions to characterize $O$. crenata populations have yet been undertaken. The present study is aiming to assess levels of genetic diversity at the molecular level using SRAP markers of $O$. crenata populations on faba bean fields from seven regions in Morocco.

\section{Materials and Methods}

\subsection{Plant Material}

A total of 162 plants (spikes) from seven $O$. crenata populations were collected during spring of 2014. Spikes of $O$. crenata populations were sampled from seven highly infested regions of Morocco (Taza, Taounate, Fez, Meknes, Khemissat, Benslimane, and Settat) (Figure 1). In each region, samples were collected from faba bean fields. Each population consisted about twenty-three $O$. crenata mature plants. The number of $O$. crenata plants analyzed per population depending on the availability of specimens found in the screened fields. 


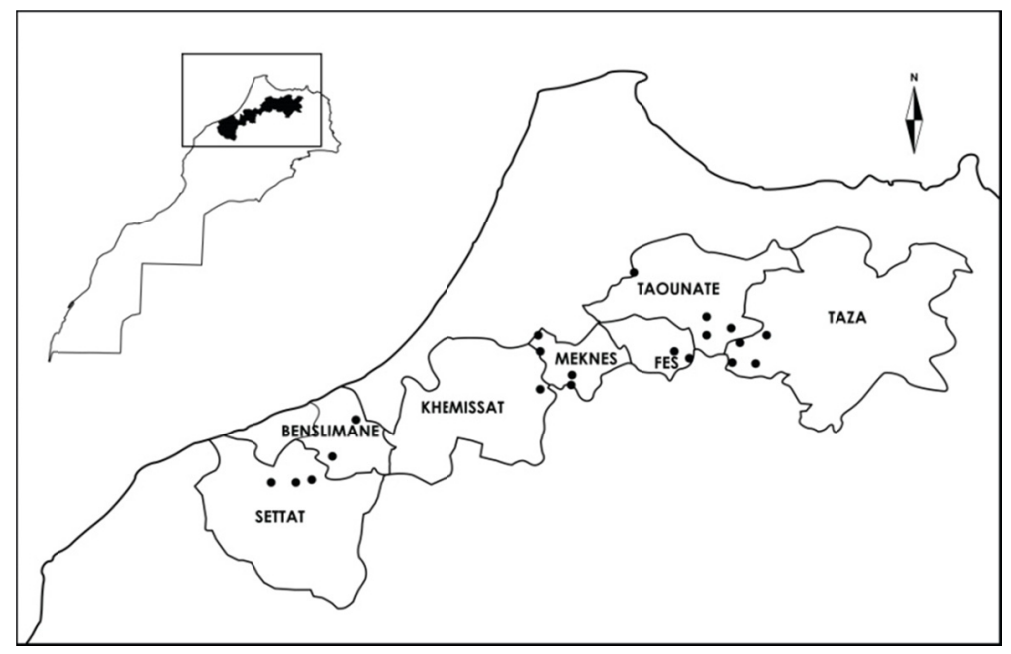

Figure 1. Seven $O$. crenata populations sampled from naturally infested faba bean fields from different region in Morocco (Taza, Taounate, Fes, Meknes, Khemisset, Benslimane, and Settat)

\subsection{DNA Extraction}

Genomic DNA was extracted using the modified CTAB method described by (Lassner, Peterson, \& Yoder, 1989). An amount of $50 \mathrm{mg}$ of powder $O$. crenata was mixed with $1 \mathrm{ml}$ of CTAB buffer (1M Tris-Hcl, $5 \mathrm{M} \mathrm{Nacl,} 0.5 \mathrm{M}$ EDTA, $2 \%(\mathrm{w} / \mathrm{v}) \mathrm{CTAB}$, and $0.2 \%$ (v/v) $\beta$-mercaptoethanol). Samples were incubated at $65{ }^{\circ} \mathrm{C}$ for $60 \mathrm{~min}$ and then cooled on ice for $5 \mathrm{~min}$. Subsequently, $0.8 \mathrm{ml}$ of an equal volume of chloroform-isoamyl alcohol (24:1-v/v) was added to the template-mixing and the tubes were centrifuged at $12000 \mathrm{rpm}$ for $10 \mathrm{~min} .0 .8 \mathrm{ml}$ of isopropanol was added to the aqueous phase and incubated overnight. The extracted DNA was washed with ethanol (75\%) and dissolved in $0.4 \mathrm{ml}$ of TE buffer (10 mM Tris, $\mathrm{pH} 8$ and $1 \mathrm{mM}$ EDTA). DNA concentration was quantified using Micro-Spectrophotometer at $260 \mathrm{~nm}$.

\subsection{SRAP Analysis}

A total of 30 SRAP primer combinations (Li \& Quiros, 2001) were analyzed across the seven $O$. crenata populations. They were purchased in commercially available kits from Eurogentec (F1R1, F1R2, F1R3, F1R4, F1R5, F1R6, F2R1, F2R2, F2R3, F2R4, F2R5, F2R6, F3R1, F3R2, F3R3, F3R4, F3R5, F3R6, F4R1, F4R2, F4R3, F4R4, F4R5, F4R6, F5R1, F5R2, F5R3, F5R4, F5R5, F5R6) (Table 1). Amplification was carried out in a thermocycler (Applied Biosystems thermocycler (9902)) according to the methods described by (Li \& Quiros, 2001). The SRAP mixture was carried out in a total volume of $20 \mu$ l, containing $1 \mathrm{X}$ buffer, $1 \mathrm{U}$ of Taq ${ }^{\mathrm{TM}} \mathrm{DNA}$ polymerase (BIOLINE, London, UK), $0.5 \mu \mathrm{M}$ of primer combinations and $25 \mathrm{ng}$ of template DNA. PCR amplification conditions consisted of two consecutive stages: DNA amplifications were performed in 5 cycles of $94{ }^{\circ} \mathrm{C}$ for $1 \mathrm{~min}, 35^{\circ} \mathrm{C}$ for $1 \mathrm{~min}$, and $72{ }^{\circ} \mathrm{C}$ for $1 \mathrm{~min}$; for denaturing, annealing and extension, respectively. Then the annealing temperature was set to $50^{\circ} \mathrm{C}$ for another 35 cycles. The PCR products were separated with a DNA marker (HyperLadder ${ }^{\mathrm{TM}} 50 \mathrm{bp}$, BIOLINE, London, UK) in polyacrylamide gel electrophoresis $(12.5 \mathrm{~V} / \mathrm{cm}$ for 1.5 hour), and visualized by staining with ethidium bromide. The amplified fragment sizes were photographed using UVP Bio Doc-It imaging system (USA).

Table 1. List and sequence of the primers used for SRAP analysis

\begin{tabular}{llll}
\hline \multicolumn{2}{l}{ Sequence of forward primers $\left(\mathbf{5}^{\prime} \mathbf{-} \mathbf{3}^{\prime}\right)$} & \multicolumn{2}{l}{ Sequence of reverse primers $\left(\mathbf{5}^{\prime} \mathbf{-} \mathbf{3}\right.$ ) } \\
\hline F1 & TGAGTCCAAACCGGATA & R1 & GACTGCGTACGAATTAAT \\
F2 & TGAGTCCAAACCGGAGC & R2 & GACTGCGTACGAATTTGC \\
F3 & TGAGTCCAAACCGGAAT & R3 & GACTGCGTACGAATTGAC \\
F4 & TGAGTCCAAACCGGACC & R4 & GACTGCGTACGAATTTGA \\
F5 & TGAGTCCAAACCGGAAG & R5 & GACTGCGTACGAATTAAC \\
& & R6 & GACTGCGTACGAATTGCA \\
\hline
\end{tabular}

Note. F: forward of SRAP primers; R: reverse of SRAP primers. 


\subsection{Statistical Analyses}

The amplification profile for each primer combination was scored according to present (1) or absent (0) of homologous bands to create a binary matrix of the different SRAP phenotypes. Only bands that were reproducible and could be scored unambiguously across all individuals were included in the analysis.

The Polymorphism Information Content values (PICv) were calculated for the most produced primer combinations, using the formula:

$$
\text { PIC value }=1-\sum_{i=1}^{n} p i^{2}
$$

Where, $p i$ is the frequency of the $i^{\text {th }}$ allele (Smith et al., 1997).

Using Gen AlEx ver. 6.5, levels of genetic diversity within and between each population were measured by calculating: expected heterozygosity, percentage of polymorphic loci, pairwise distance matrices, and pairwise genetic distances. The number of permutations for significant testing was set at 1000 for analysis. Analysis of molecular variance (AMOVA) based on PhiPT values was carried out using the same program, to calculates Fixation index $\left(F_{S T}\right)$ analogue $(\mathrm{PhiPT}=\mathrm{AP} /(\mathrm{WP}+\mathrm{AP})=\mathrm{AP} / \mathrm{TOT}$ with $\mathrm{AP}=$ Est. Var. Among Populations, $\mathrm{WP}=$ Est. Var. Within Populations), which estimates variation among and within populations. These values can range between 0 (no differentiation) and 1 (complete differentiation).

In addition, to assess genetic relationships among populations, the matrix of inter-individual Dice's distance coefficients (Nei \& Li, 1979) was used for a principal coordinate analysis (PCoA). Finally, Jaccard's similarity coefficient was estimated using XLSTAT 5.14 software, UPGMA (un-weighted pair-group method with arithmetic average) was performed and a dendrogram was derived from the tree option.

\section{Results}

\subsection{Variation for SRAP Markers}

The objective of the study was to determine the genetic relationships among 162 Moroccan $O$. crenata populations from different regions using SRAP analysis. Among thirty primer combinations tested, only six (F3R4, F4R2, F4R3, F4R6, F5R3, F5R5) generated robust and reproducible amplification products. The number of polymorphic fragments detected by each primer combinations varied from 13 bands (F4R2) to 26 bands (F4R3), and fragments sizes ranged between $50 \mathrm{bp}$ to $2000 \mathrm{bp}$. A total of 101 bands amplified were scored, 3 were monomorphic, and 98 bands were Polymorphic, discriminating therefore between the seven analyzed $O$. crenata populations. The average number of total bands and polymorphic bands per primer were 16.83 and 16.33 , respectively. Three of the SRAP primer combinations analyzed (F4R3, F4R6, and F5R3) yielded 100\% polymorphic bands. On the other hand, the minimum proportion of polymorphic bands $(92.30 \%)$ was obtained by F4R2 (Table 2).

In order to measure the efficiency of polymorphic loci for detecting the genetic diversity among the studied populations, the $\mathrm{PICv}$ was calculated. For the 6 primer combinations, PICv ranged from 0.91 (F4R2) to 0.98 (F4R3, F4R6, and F5R3) with an average of 0.95 (Table 2). 
Table 2. Polymorphism number and rate and PIC values of six SRAP primers pairs used to amplify 162 genomic DNA templates of seven Moroccan $O$. crenata populations

\begin{tabular}{|c|c|c|c|c|c|}
\hline SRAP Primers & Sequence $\left(5^{\prime}-3^{\prime}\right)$ & $\begin{array}{l}\text { Number of } \\
\text { total fragments }\end{array}$ & $\begin{array}{l}\text { Number of } \\
\text { polymorphic bands }\end{array}$ & Polymorphism (\%) & PIC values \\
\hline \multirow[t]{2}{*}{ F4R3 } & F-TGAGTCCAAACCGGACC & 26 & 26 & 100 & 0.98 \\
\hline & R-GACTGCGTACGAATTGAC & & & & \\
\hline \multirow[t]{2}{*}{ F4R6 } & F-TGAGTCCAAACCGGACC & 18 & 18 & 100 & 0.98 \\
\hline & R-GACTGCGTACGAATTGCA & & & & \\
\hline \multirow[t]{2}{*}{ F5R5 } & F-TGAGTCCAAACCGGAAG & 14 & 13 & 92.85 & 0.94 \\
\hline & R-GACTGCGTACGAATTAAC & & & & \\
\hline \multirow[t]{2}{*}{ F3R4 } & F-TGAGTCCAAACCGGAAT & 15 & 14 & 93.33 & 0.96 \\
\hline & R- GACTGCGTACGAATTTGA & & & & \\
\hline \multirow[t]{2}{*}{ F4R2 } & F- TGAGTCCAAACCGGACC & 13 & 12 & 92.30 & 0.91 \\
\hline & R- GACTGCGTACGAATTTGC & & & & \\
\hline \multirow[t]{2}{*}{ F5R3 } & F-TGAGTCCAAACCGGAAG & 15 & 15 & 100 & 0.98 \\
\hline & R-GACTGCGTACGAATTGAC & & & & \\
\hline Average & & 16.83 & 16.33 & 96.41 & 0.95 \\
\hline Total & & 101 & 98 & - & - \\
\hline
\end{tabular}

Note. F: forward of SRAP primers; R: reverse of SRAP primers.

\subsection{Genetic Diversity}

The SRAP marker analysis of the seven $O$. crenata populations revealed a high level of genetic variation with $97.02 \%$ of polymorphic bands. Nevertheless, a low genetic diversity within populations was shown with a variation ranging from $41.58 \%$ to $67.33 \%$. The mean percentage of polymorphic loci was $53.18 \%$. At the intra-population levels, the highest percentage of polymorphism was found in Taounate population, whereas the lowest value was that of Meknes population (Table 3). The diversity analysis within the populations using Shannon's index (I) as well as the expected heterozygosity (He) ranked the populations based on their region of origin from the most diverse to the least diverse as follows of Taounate, Benslimane, Khemissat, Taza, Meknes, Fez, and Settat region, with an average of 0.238 (I) and 0.154 (He) respectively. The estimated allele frequency with number of different alleles (Na) of Taounate population was the highest (1.574) and that of Meknes and Fez populations was the lowest (1.307). For the estimated allele frequency with number of effective alleles (Ne), the Taounate population was the highest one (1.323) and the Settat population was the lowest one (1.144) (Table 3).

Table 3. Summary of molecular data of SRAP primer combinations used for O. crenata populations from seven regions of Morocco

\begin{tabular}{lllllll}
\hline Populations & $\mathrm{P}(\%)$ & $\mathrm{N}$ & $\mathrm{Na}( \pm \mathrm{SE})$ & $\mathrm{Ne}( \pm \mathrm{SE})$ & $\mathrm{I}( \pm \mathrm{SE})$ & $\mathrm{He}( \pm \mathrm{SE})$ \\
\hline Taounate & $67.33 \%$ & 30 & $1.574(0.067)$ & $1.323(0.035)$ & $0.302(0.026)$ & $0.196(0.019)$ \\
Taza & $52.48 \%$ & 24 & $1.327(0.078)$ & $1.295(0.038)$ & $0.255(0.028)$ & $0.169(0.020)$ \\
Settat & $43.56 \%$ & 24 & $1.109(0.087)$ & $1.144(0.025)$ & $0.156(0.022)$ & $0.095(0.014)$ \\
Benslimane & $63.37 \%$ & 16 & $1.525(0.068)$ & $1.289(0.031)$ & $0.287(0.025)$ & $0.184(0.017)$ \\
Khemissat & $57.43 \%$ & 19 & $1.485(0.065)$ & $1.303(0.034)$ & $0.281(0.027)$ & $0.184(0.019)$ \\
Meknes & $41.58 \%$ & 25 & $1.307(0.066)$ & $1.228(0.033)$ & $0.207(0.027)$ & $0.137(0.018)$ \\
Fez & $46.53 \%$ & 24 & $1.307(0.073)$ & $1.168(0.025)$ & $0.180(0.023)$ & $0.112(0.015)$ \\
Average & $53.18 \%$ & 23.143 & $1.376(0.028)$ & $1.250(0.012)$ & $0.238(0.010)$ & $0.154(0.007)$ \\
\hline
\end{tabular}

Note. $\mathrm{P}(\%)=$ percentage of polymorphic loci; $\mathrm{N}=$ number of individuals; $\mathrm{Na}=$ number of different alleles; $\mathrm{Ne}=$ number of effective alleles; I = Shannon's diversity index; $\mathrm{He}=$ expected heterozygosity.

\subsection{Genetic Structure of Global O. crenata Populations Based on Geographic Origin}

Genetic differentiation between populations was relatively high, and all populations were significantly different $(\mathrm{P}<0.05$; Table 4). Genetic distance and identity coefficient were calculated by the method (Nei, 1972). These values were practically high with the mean genetic identities among populations varying from 0.553 to 0.806 . Considering the genetic distance, the values ranged from 0.216 to 0.592 . Genetic identity and genetic distance 
among the seven regions demonstrated that the Benslimane and Taza population pair had the highest genetic similarity $(0.806)$ and the lowest genetic distance $(0.216 ; \mathrm{P}=0.377)$, while Meknes and Benslimane had the least similarity $(0.553)$ and the highest genetic distance $(0.592 ; \mathrm{P}=0.628)$ (Table 5$)$.

Table 4. Paiwise population matrix of average differentiation among $O$. crenata populations from Taounate, Benslimane, Khemissat, Taza, Meknes, Fez, and Settat regions

\begin{tabular}{llllllll}
\hline & Taounate & Taza & Settat & Benslimane & Khemissat & Meknes & Fez \\
\hline Taounate & $* * * *$ & & & & & & \\
Taza & 0.566 & $* * * *$ & & & & & \\
Settat & 0.552 & 0.604 & $* * * *$ & & & & \\
Benslimane & 0.486 & 0.377 & 0.573 & $* * * *$ & & & \\
Khemissat & 0.530 & 0.587 & 0.644 & 0.496 & $* * * *$ & & \\
Meknes & 0.607 & 0.645 & 0.719 & 0.628 & 0.592 & $* * *$ & $* * * *$ \\
Fez & 0.629 & 0.612 & 0.704 & 0.572 & 0.626 & 0.613 & $*$.
\end{tabular}

Note. Number values based on 1000 permutations.

Table 5. Pairwise comparison matrix of Nei genetic identity (Above diagonal) and Nei genetic distance (Below diagonal) for $O$. crenata populations from Taounate, Benslimane, Khemissat, Taza, Meknes, Fez, and Settat regions based on their geographic origin

\begin{tabular}{llllllll}
\hline & Taounate & Taza & Settat & Benslimane & Khemissat & Meknes & Fez \\
\hline Taounate & $* * * *$ & 0.652 & 0.713 & 0.709 & 0.651 & 0.570 & 0.584 \\
Taza & 0.428 & $* * * *$ & 0.679 & 0.806 & 0.619 & 0.603 & 0.641 \\
Settat & 0.338 & 0.386 & $* * * *$ & 0.700 & 0.633 & 0.565 & 0.588 \\
Benslimane & 0.344 & 0.216 & 0.357 & $* * * *$ & 0.687 & 0.553 & 0.658 \\
Khemissat & 0.429 & 0.480 & 0.457 & 0.375 & $* * * *$ & 0.636 & 0.619 \\
Meknes & 0.563 & 0.507 & 0.572 & 0.592 & 0.452 & $* * * *$ & 0.698 \\
Fez & 0.537 & 0.444 & 0.532 & 0.419 & 0.480 & 0.359 & $* * * *$ \\
\hline
\end{tabular}

Analysis of Molecular Variance (AMOVA) was used to evaluate diversity structure between the seven $O$. crenata populations (Table 6). Considerable internal variation was observed within $O$. crenata populations $(60 \%)$. Furthermore, significant divergence $(40 \% ; \varnothing=0.597 ; \mathrm{p}=0.010)$ among the seven populations was also detected.

Table 6. Analysis of molecular variation (AMOVA) for $O$. crenata population from seven regions

\begin{tabular}{llllllll}
\hline Source of variation & Df & SS & MS & Est. Var. & $\%$ & PhiPT & P \\
\hline Among populations & 6 & 1964.500 & 327.417 & 13.819 & $60 \%$ & 0.597 & $<0.001$ \\
Within populations & 155 & 1445.426 & 9.325 & 9.325 & $40 \%$ & $<0.001$ \\
\hline Total & 161 & 3410.926 & \multicolumn{7}{c}{23.144} & 100 & \\
\hline
\end{tabular}

Note. $\mathrm{Df}=$ degree of freedom; $\mathrm{SS}=$ Sums of squares; MS = mean squares; Est. var = estimate of variance; \% $=$ percentage of total variation; PhiPT $=$ Phi-statistics probability level after 1000 permutations; $\mathrm{P}=$ is based on 1000 permutation.

\subsection{Cluster Analysis}

The data obtained from SRAP analysis of $162 O$. crenata samples was used in the frame of a cluster analysis. The estimated Jaccard's differences between $O$. crenata populations varied from 0 to $0.996(p=0.001)$ between different pairs of individuals and the UPGMA method showed a good fit to the matrix on which it was based. UPGMA separated $O$. crenata populations into three main clusters: The first group encompassed the populations from North-central area including Fes, Meknes, Khemissat, and six samples of the Benslimane region. The second group consisted on 2 populations (Taounate and Settat populations). The third group included Taza population and the rest of the Benslimane population (10 samples). In this dendrogram, most samples formed clusters according to the the geographical scope (Figure 2). 


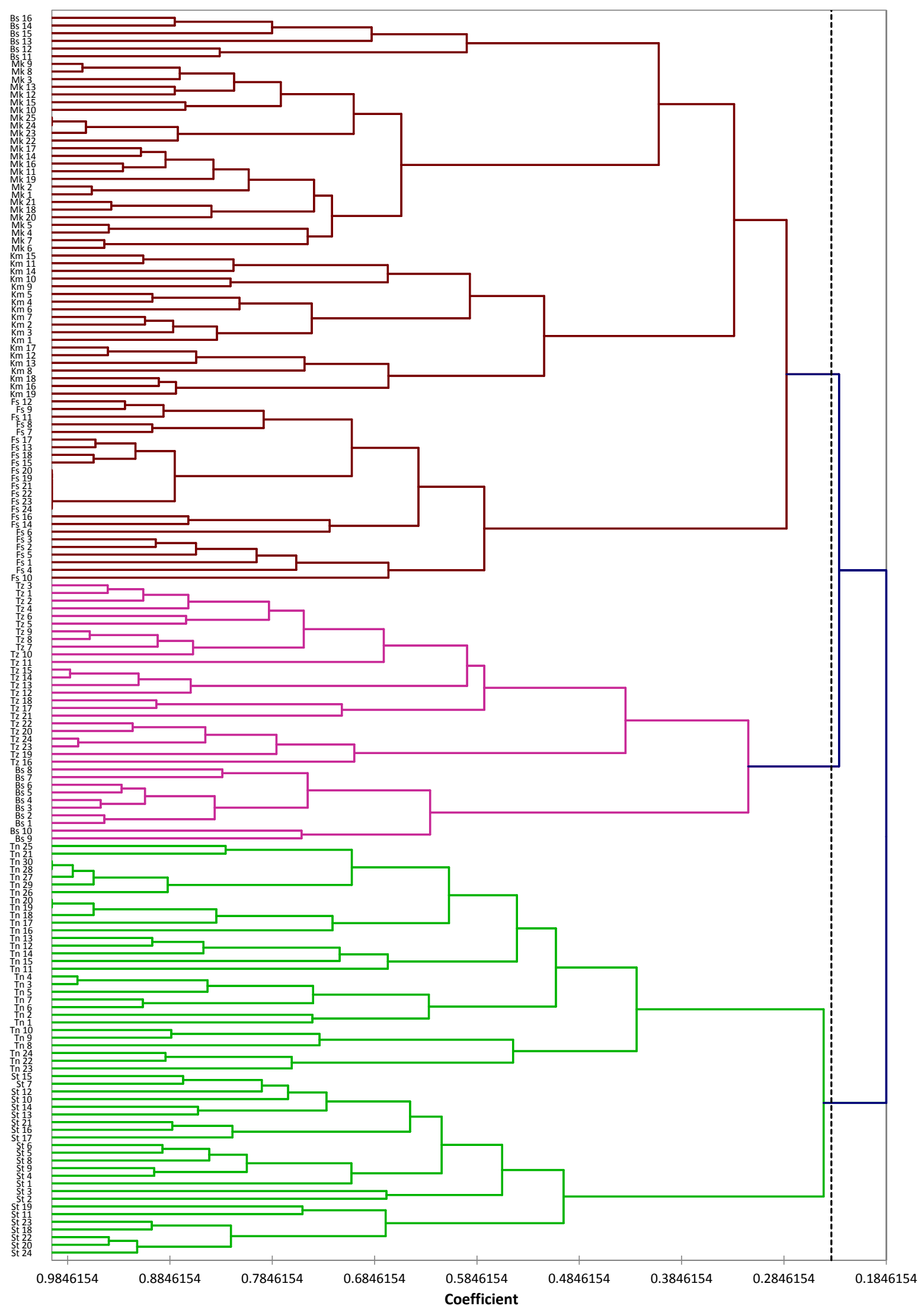

Figure 2. UPGMA cluster analysis of SRAP data for all O. crenata individuals sampled (Tn: Taounate, Tz: Taza, St: Settat, Bs: Benslimane, Km: Khemissat, Mk: Meknes, and Fs: Fez) 


\subsection{Principal Coordinate Analysis (PCoA)}

PCoA allowed the study of the correlations between different $O$. crenata samples based on Dice's similarity matrix. The screen plot generated by PCoA demonstrated that data variability is represented mostly within the first three axes of the ordination. The average distances among samples were plotted at two-dimensional space (Figure 3). The PCoA of locus SRAP variation explained 31.09\%, with the first component (PCo1) explaining $17.57 \%$ of the total variation and the second component (PCo2) explaining $13.52 \%$ of the total variation. The results indicated that the degree of genetic variation within populations was the least. This axial coordinate, separated the populations based on their geographical origin and PCoA analysis confirmed the cluster analysis results.

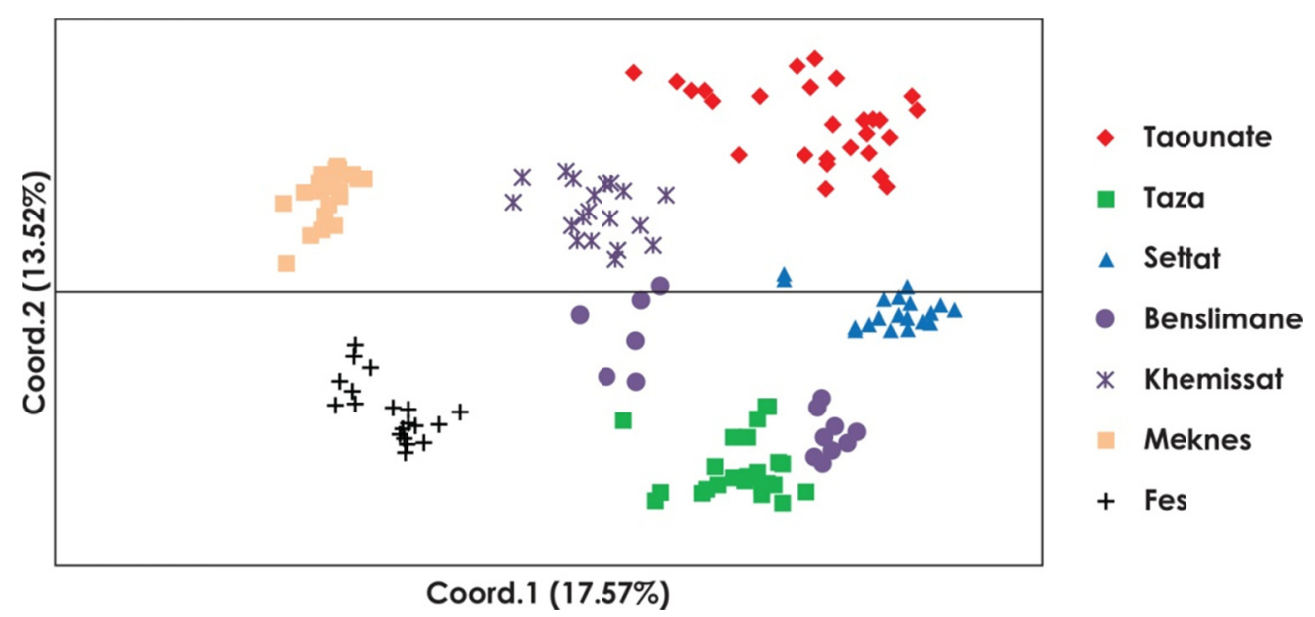

Figure 3. Dimensional Principal Coordinate Analysis (PCoA) of a matrix based on genotyping with 101 loci for $162 O$. crenata sampled collected mainly from faba bean from seven geographic origins

\section{Discussion}

The aim of this study is to evaluate genetic diversity of $O$. crenata population collected from different geographical regions of Morocco using SARP markers. Six primer combinations produced 101 bands, where 98 were polymorphic and revealed high levels of genetic diversity, as indicated by the level of polymorphism (97.02\%) and Shannon's index (0.238). (Román, Rubiales, Torres, Cubero, \& Satovic, 2001) used RAPD primers to investigate genetic diversity of six $O$. crenata populations from naturally infected faba bean plants from different locations in southern Spain (Andalucía), which also revealed high polymeric loci (91\%).

Parameters such as PIC values have been used for assessing the informative potential of SRAP markers. In fact, (Botstein, White, Skolnick, \& Davis, 1980) who suggested that high, medium or slightly informative marker are in concurrence respectively with PIC values $>0.5,0.5>$ PIC values $>0.25$, and PIC values $<0.25$, respectively. In this study the mean of PICv obtained from SRAP markers seems highly informative (0.95). This data clearly demonstrates that SRAP markers are informative at the species level of $O$. crenata as it has been for other plants (Al-Faifi et al., 2013; Esposito, Martin, Cravero, \& Cointry, 2007; Rana, Singh, \& Bhat, 2009).

One of the important features of a good marker system is its ability to distinguish among different populations. In our study, the cluster analysis divided the set of studied populations into three major groups. Despite their geographical distance, close relationships were revealed between $O$. crenata populations from Taza and Benslimane and also between these from Taounate and Settat, showing that there was no relationship between genetic divergence and geographical origin. This is probably due to seed dispersal by humans, animals, machinery, and wind. These parameters are influencing the genetic variability and may contribute to the gene flow between $O$. crenata populations (Ellstrand \& Elam, 1993). The absence of correlation of genetic variability with geographic distance was also reported by (Román, Rubiales, Torres, Cubero, \& Satovic, 2001) on $O$. crenata populations from Spain and also, for other parasitic weed, such as Cuscuta campestris parasiting Beta vulgaris from Iran (Tajdoost, Khavari-Nejad, Meighani, Zand, \& Noormohammadi, 2013) and Striga hermonthica parasiting sorghum, millet, tef, and maize from Ethiopia (Welsh \& Mohamed, 2011).

The levels of genetic differentiation observed between the sampled populations span a broad range. AMOVA test, showed that high variation occur among $O$. crenata populations $(60 \%)$ than within them $(40 \%)$. Similar 
proportion of variability were reported among O. cumana populations from Eastern Bulgaria (Pineda-Martos et al., 2014) and among Cuscuta campestris populations from Iran (Tajdoost, Khavari-Nejad, Meighani, Zand, \& Noormohammadi, 2013) with $53.6 \%$ and $81 \%$, respectively. In fact, population genetic structure is affected by a number of evolutionary factors including gene flow, seed dispersal, and mode of reproduction (Tajdoost, Khavari-Nejad, Meighani, Zand, \& Noormohammadi, 2013). At the opposite, (Román, Rubiales, Torres, CuberoI, \& Satovic, 2001) based on the RAPD markers, found high intra-population variability (94\%) within six southern Spain $O$. crenata populations. Furthermore, our previous study on genetic diversity, using RAPD markers, within six $O$. crenata populations collected from faba bean and lentil fields in three highly infested regions of Morocco (Taza, Meknes and Settat) showed $81 \%$ and $82 \%$ of intra-population variability respectively (Ennami et al., 2017). These dissimilarities between our current study and former RAPD analysis may be due to the type of markers used. In fact, previous studies reported the presence of artifactual bands (false positives and false negatives) on RAPD markers. This may seriously restrict the reliability of this marker for genetic diversity studies (Semagn, Bjornstad, \& Ndjiondjop 2006; Li \& Quiros, 2001). At the opposite, SRAP results seam more trustworthy, as they have the highest average discriminating power among the four systems AFLP, SSR, ISSR, and RAPD (Budak, Shearman, Parmaksiz, Gaussoin, \& Riosdan, 2004). Furthermore, SRAP markers have the asset to amplify coding regions of the genome with primers targeting ORFs, elucidating therefore regions with inherent biological significance (Robarts, \& Wolfe, 2014).

\section{Conclusions}

In this study, SRAP markers revealed sufficient polymorphism and provided adequate information for the assessment of genetic diversity of $O$. crenata populations. In fact, AMOVA of this parasitic weed showed a high level of inter-population variation $(60 \% ; \mathrm{p}<0.010)$. Furthermore, cluster analysis illustrated a clear differentiation among $O$. crenata samples according to the geographical origin. These results may suggest the existence of pathovars. Further epidemiological studies of these seven $O$. crenata populations should clarify occurrence of $O$. crenata pathotypes. In this case, multisite screening trials during breeding programs should be considered for the development of faba bean resistant/tolerant genotypes.

\section{Acknowledgements}

This research was supported by National Institute of Agricultural Research (INRA-Morocco) and Ministry of Higher Education, Scientific Research and Professional Training of Morocco (MESRSFC) through funding of MEDILEG project within the European Union $7^{\text {th }}$ Framework program for research, technological development and demonstration (ERA-Net Project, ARIMNet).

\section{References}

Al-Faifi, S. A., Migdadi, H. M., Al-doss, A., Ammar, M. H., El-Harty, E. H., Khan, M. A., ... Alghamdi, S. S. (2013). Morphological and molecular genetic variability analyses of Saudi lucerne (Medicago sativa L.) landraces. Crop and Pasture Science, 64, 137-146. https://doi.org/10.1071/CP12271

Aneja, B. (2010). Micronutrient and Molecular Diversity Analysis in Mungbean [Vigna Radiata (L.) Wilezek] Genotypes (Master's thesis, Chaudhary Charan Singh Haryana Agricultural University, Hisar, Indian state of Haryana). Retrieved from http://krishikosh.egranth.ac.in/handle/1/85148

Aneja, B., Yadav, N. R., Chawla, V., \& Yadav, R. C. (2012). Sequence-related amplified polymorphism (SRAP) molecular marker system and its applications in crop improvement. Molecular Breeding, 30, 1635-1648. https://doi.org/10.1007/s11032-012-9747-2

Botstein, D., White, R. L., Skolnick, M., \& Davis, R. W. (1980). Construction of a genetic linkage map in man using restriction fragment length polymorphisms. American Journal of Human Genetics, 32(3), 314-331.

Budak, H. R. C., Shearman, I., Parmaksiz, R. E., Gaussoin, T. P., \& Riosdan, D. (2004). Molecular characterization of Buffalograss germplasm using sequence-related amplified polymorphism markers. Theor Appl Genetics, 108, 328-334. https://doi.org/10.1007/s00122-003-1428-4

Budak, H., Shearman, R., Parmaksiz, I., \& Dweikat, I. (2004). Comparative analysis of seeded and vegetative biotype buffalograsses based on phylogenetic relationship using ISSRs, SSRs, RAPDs, and SRAPs. Theoretical and Applied Genetics, 109, 280-288. https://doi.org/10.1007/s00122-004-1630-z

Castonguay, Y., Cloutier, J., Bertrand, A., Michaud, R., \& Laberge, S. (2010). SRAP polymorphisms associated with superior freezing tolerance in alfalfa (Medicago sativa spp. sativa). Theoretical and Applied Genetics, 120, 1611-1619. https://doi.org/10.1007/s00122-010-1280-2 
Crépon, K., Marget, P., Peyronnet, C., Carrouée, B., Arese, P., \& Duc, G. (2010). Nutritional value of faba bean (Vicia faba L.) seeds for feed and food. Field Crops Research, 115, 329-339. https://doi.org/10.1016/j.fcr. 2009.09.016

Dybdahl, M. F., \& Lively, C. M. (1996). The geography of coevolution: Comparative population structures for a snail and its trematode parasite. Evolution, 50, 2264-2275. Retrieved from http://www.jstor.org/stable/ 2410696

Ellstrand, N. C., \& Elam, D. R. (1993). Population genetic consequences of small population size: Implications for plant conservation. Annual review of Ecology and Systematics, 24, 217-242. https://doi.org/10.1146/ annurev.es.24.110193.001245

Ennami, M., Briache, F. Z., Gaboun, F., Abdelwahd, R., Ghaouti, L., Belqadi, L., Westwood, J., \& Mentag, R. (2017). Host differentiation and variability of Orobanche crenata populations from legume species in Morocco as revealed by cross infestation and molecular analysis. Pest Management Science (In press). https://doi.org/10.1002/ps.4536

Esposito, M., Martin, E., Cravero, V., \& Cointry, E. (2007). Characterization of pea accessions by SRAP's markers. Scientia Horticulturae, 113, 329-335. https://doi.org/10.1016/j.scienta.2007.04.006

Ferriol, M., Pico, B., \& Nuez, F. (2003). Genetic diversity of a germplasm collection of Cucurbita pepo using SRAP and AFLP markers. Theoretical and Applied Genetics, 107, 271-282. https://doi.org/10.1007/ s00122-003-1242-z

Food and Agriculture Organization Statistical. (2015). Prod stat: Crops. FAO statistical databases (FAOSTAT), Food and Agriculture Organization of the United Nations (FAO). Retrieved from http://faostat3.fao.org/ home/E

Gagne, G., Roeckel-Drevet, P., Grezes-Besset, B., Shindrova, P., Ivanov, P., Grand-Ravel, C., ... Nicolas, P. (2000). Amplified fragment length polymorphism (AFLP) as suitable markers to study Orobanche cumana genetic diversity. Journal of Phytopathology, 148, 457-459. https://doi.org/10.1046/j.1439-0434.2000. 00528.x

Herridge, D. F., Peoples, M. B., \& Boddey, R. M. (2008). Global inputs of biological nitrogen fixation in agricultural systems. Plant and Soil, 311, 1-18. https://doi.org/10.1007/s11104-008-9668-3

Joel, D. M., Hershenhorn, J., Eizenberg, H., Aly, R., Ejeta, G., Rich, P. J., ... Rubiales, D. (2007). Biology and management of weedy root parasites. https://doi.org/10.1002/9780470168011.

Lassner, M. W., Peterson, P., \& Yoder, J. I. (1989). Simultaneous amplification of multiple DNA fragments by polymerase chain reaction in the analysis of transgenic plants and their progeny. Plant Molecular Biology Reporter, 7, 116-128. https://doi.org/10.1007/BF02669627

Li, G., \& Quiros, C. F. (2001). Sequence-related amplified polymorphism (SRAP), a new marker system based on a simple PCR reaction: Its application to mapping and gene tagging in Brassica. Theoretical and Applied Genetics, 103, 455-461. https://doi.org/10.1007/s001220100570

Liu, L. W., Zhao, L. P., Gong, Y. Q., Wang, M. X., Chen, L. M., Yang, J. L., ... Wang, L. Z. (2008). DNA fingerprinting and genetic diversity analysis of late-bolting radish cultivars with RAPD, ISSR and SRAP markers. Scientia Horticulturae, 116, 240-247. https://doi.org/10.1016/j.scienta.2007.12.011

Liu, L., Zhu, X., Gong, Y., Song, X., Wang, Y., Zhao, L., \& Wang, L. (2006). Genetic diversity analysis of radish germplasm with RAPD, AFLP and SRAP markers. In K. E. Hummer (Ed.), XXVII International Horticultural Congress-IHC2006: II International Symposium on Plant Genetic Resources of Horticultural crops. https://doi.org/10.17660/ActaHortic.2007.760.15

Miguel, A. D., Nicolas, R., Elena, P., Rubiales, D., \& Karam, B. S. (2006). Biotechnology approaches to overcome biotic and abiotic stress constraints in legumes. Euphytica, 147, 1-24. https://doi.org/10.1007/ s10681-006-6156-9

Nei, M. (1972). Genetic distance between populations. American Naturalist, 106, 283-292. https://doi.org/ $10.1086 / 282771$

Nei, M., \& Li, W. H. (1979). Mathematical model for studying genetic variation in terms of restriction endonucleases. Proceedings of the National Academy of Sciences, 76, 5269-5273. https://doi.org/10.1073/ pnas.76.10.5269 
Parker, C. (2009). Observations on the current status of Orobanche and Striga problems worldwide. Pest Management Science, 65, 453-459. https://doi.org/10.1002/ps.1713

Pineda-Martos, R., Pujadas-Salvà, A. J., Fernández-Martínez, J. M., Stoyanov, K., Velasco, L., \& Pérez-Vich, B. (2014). The Genetic Structure of Wild Orobanche cumana Wallr. (Orobanchaceae) Populations in Eastern Bulgaria Reflects Introgressions from Weedy Populations. The Scientific World Journal, 15. https://doi.org/10.1155/2014/150432

Rana, M., Singh, S. P., \& Bhat, K. (2009). Fingerprinting Indian lentil (Lens culinaris ssp. culinaris Medik.) cultivars and landraces for diversity analysis using Sequence-Related Amplified Polymorphism (SRAP) markers. Proceedings of Fourth International Food and Legumes Research Conference (pp. 617-624). New Delhi, India.

Robarts, D. W., \& Wolfe, A. D. (2014). Sequence-Related Amplified Polymorphism (SRAP) Markers: A Potential Resource for Studies in Plant Molecular Biology. Applications in Plant Sciences, 2, 1400017. https://doi.org/10.3732/apps. 1400017

Román, B., Rubiales, D., Torres, A. M., Cubero, J. I., \& Satovic, Z. (2001). Genetic diversity in Orobanche crenata populations from southern Spain. Theoretical and Applied Genetics, 103, 1108-1114. https://doi.org/10.1007/s001220100644

Román, B., Satovic, Z., Rubiales, D., Torres, A. M., Cubero, J. I., Katzir, N., \& Joel, D. M. (2002). Variation among and within populations of the parasitic weed Orobanche crenata from Spain and Israel revealed by inter simple sequence repeat markers. Phytopathology, 92, 1262-1266. https://doi.org/10.1094/ PHYTO.2002.92.12.1262

Rubiales, D., Fernández-Aparicio, M., Pérez-de-Luque, A., Castillejo, M. A., Prats, E., Sillero, J. C., ... Fondevilla, S. (2009). Breeding approaches for crenate broomrape (Orobanche crenata Forsk.) management in pea (Pisum sativum L). Pest Managment Science, 65, 553-559. https://doi.org/10.1002/ps.1740

Rubiales, D., Pérez-de-Luque, A., Fernández-Aparicio, M., Sillero, J. C., Román, B., Kharrat, M., ... Riches, C. (2005). Screening techniques and sources of resistance against parasitic weeds in grain legumes. Euphytica, 147, 187-199. https://doi.org/10.1007/s10681-006-7399-1

Semagn, K., Bjornstad, A., \& Ndjiondjop, M. N. (2006). An overview of molecular marker methods for plants. Afr. J. Biotechnol, 5, 2540-2568. Retrieved from http://www.academicjournals.org/AJB

Smith, J., Chin, E., Shu, H., Smith, O., Wall, S., Senior, M., ... Ziegle, J. (1997). An evaluation of the utility of SSR loci as molecular markers in maize (Zea mays L.): Comparisons with data from RFLPs and pedigree. Theoretical and Applied Genetics, 95, 163-173. https://doi.org/10.1007/s001220050544

Tajdoost, S., Khavari-Nejad, R. A., Meighani, F., Zand, E., \& Noormohammadi, Z. (2013). Evaluation of genetic diversity and differentiation of Cuscuta campestris (field dodder) ecotypes using ISSR markers. Food Agric Environ, 11, 1072-1075.

Ter Borg, S. J., Willemsen, A., Khalil, S. A., Saber, H. A., Verkleij, J. A. C., \& Pieterse, A. H. (1994). Field study of the interaction between Orobanche crenata Forsk. and some new lines of Vicia faba L. in Egypt. Crop Protection, 13, 611-616. https://doi.org/10.1016/0261-2194(94)90007-8

Thompson, J. N. (1994). The coevolutionary process. The University of Chicago Press Books. https://doi.org/10.7208/chicago/9780226797670.001.0001

Torres, A. M., Avila, C. M., Satovic, Z., Rubiales, D., Sillero, J. C., Cubero, J. I., ... Moreno, M. T. (2006). Faba bean breeding for resistance against biotic stresses: Towards application of marker technology. Euphytica, 147, 67-80. https://doi.org/10.1007/s10681-006-4057-6

Verkleij, J., \& Pieterse, A. (1991). Genetic variability in Orobanche (broomrape) and Striga (witchweed) and its implications for host crop resistance breeding. Ecological responses to environmental stresses: Ecological responses to environmental stresses. https://doi.org/10.1007/978-94-009-0599-3_25

Welsh, A. B., \& Mohamed, K. I. (2011). Genetic diversity of Striga hermonthica populations in Ethiopia: Evaluating the role of geography and host specificity in shaping population structure. International Journal of Plant Sciences, 172, 773-782. Retrieved from http://www.jstor.org/stable/10.1086/660104

Westwood, J. H., \& Fagg, C. M. (2004). ISSR characterization of Orobanche minor populations in the US. In D. M. Joel, H. Bouwmeester, P. Delavault, G. Ejeta, F. Kanampiu, M. Press, ... W. J. Zhou (Eds.), Proceedings of the 8th international parasitic weeds symposium (p. 15). IPPS: Durban, South Africa. 
Westwood, J. H., Yoder, J. I., Timko, M. P., \& dePamphilis, C. W. (2010). The evolution of parasitism in plants. Trends in Plant Science, 15, 227-235. https://doi.org/10.1016/j.tplants.2010.01.004

Xue, D., Feng, S., Zhao, H., Jiang, H., Shen, B., Shi, N., ... Wang, H. (2010). The linkage maps of Dendrobium species based on RAPD and SRAP markers. Journal of Genetics and Genomics, 37, 197-204. https://doi.org/10.1016/S1673-8527(09)60038-2

Yang, P., Liu, X., Yang, W., \& Feng, Z. (2015). Diversity analysis of the developed qingke (hulless barley) cultivars representing different growing regions of the Qinghai-Tibet Plateau in China using sequencerelated amplified polymorphism (SRAP) markers. African Journal of Biotechnology, 9, $8530-8538$.

Yu, H., Zhao, Z., Sheng, X., Wang, J., \& Gu, H. (2013). Evaluation of genetic diversity in self-incompatible broccoli DH lines assessed by SRAP markers. African Journal of Biotechnology, 10, 12561-12566. https://doi.org/10.5897/AJB11.822

\section{Copyrights}

Copyright for this article is retained by the author(s), with first publication rights granted to the journal.

This is an open-access article distributed under the terms and conditions of the Creative Commons Attribution license (http://creativecommons.org/licenses/by/4.0/). 